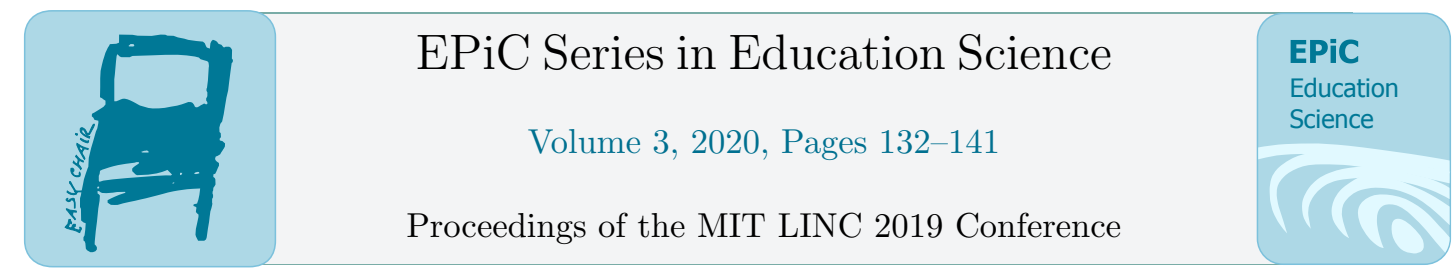

\title{
Online Learning in the Arab World: A Shifting Landscape
}

\author{
Sherif Halawa \\ Edraak, Queen Rania Foundation \\ shalawa@qrf.org
}

\author{
Shireen Yacoub \\ Edraak, Queen Rania Foundation \\ syacoub@qrf.org
}

\begin{abstract}
This paper presents an analysis of the engagement of learners in the Arab World with Edraak, a regional online learning platform, between 2015 and 2018. Our analysis investigates the changes in demographic characteristics of registration and engagement with online courses across the 4-year period. We also investigate correlations at the country level between engagement with online learning on Edraak and several human and technology development indices of the countries. The results show gradual but substantial shifts in demographic characteristics of engagement over the 4 year period, including noticeable drops in average registrant age and a shrinkage of the gender gaps in registration. The correlations of registration and engagement with human and technology development indices show that gender gaps in 2015 were positively correlated with the Arab countries' gender inequality indices (GII), and that the shrinkage in gender gaps over the 4 years is negatively correlated with the GII. Our results also show that penetration of online learning is negatively correlated with the countries' Information and Communication Technology (ICT) indices, but positively correlated with the digital skills ICT sub-index. We point out possible explanations for these correlations that could be further researched in the future to inform policy makers on how certain development conditions can promote or restrain the adoption of online learning at a national level.
\end{abstract}




\section{Introduction}

Reports on the state of education in the Arab World point out continued deficits and inequalities in access to high-quality education, educational attainment, and access to employment across the region [1,6]. For example, gender inequality in access to education [1] and employment [2] remains high in some Arab countries. Geographical factors, as another example, deprive many qualified students from matriculating in stronger but distant Universities. Helping such students access better educational opportunities has been one of the priorities of online learning and massive open online courses (MOOCs) in particular [7].

Over the past 5 years, nonetheless, the region has witnessed growing adoption of online learning at the individual and institutional levels. Millions of learners have enrolled in MOOCs offered in Arabic on regional platforms, such as Edraak [3], Rwaq [4], and Duroob [5]. A recent study [8] comparing engagement of Arab learners on Edraak with Arab learners' engagement on the non-Arabic MOOC platform, edX, shows that the Edraak population has a more even gender distribution, higher representation of learners with lower educational attainment, and higher completion rates. This study suggests that regional platforms can play an important role in making access to education more equitable.

As such, it is important for researchers and policy makers to understand (1) how key demographic groups in the Arab World are engaging with online learning, (2) how their engagement is evolving over time, and (3) how human and technology development correlates with adoption of online learning.

We analyzed 4 years of online learning data from the Edraak platform, a regional MOOC provider offering MOOCs in Arabic, to answer the questions above. This paper presents our key findings. Our research is structured around the following 3 specific research questions:

RQ 1: What are the gender and age demographic patterns of Arab learners' engagement with online learning, and how have these patterns evolved and changed over the 4 years? This RQ is motivated by the region's long-standing gender inequality in educational access and employment, and our need to understand the current role, and its future projection, that online learning is playing to close this gap.

RQ 2: How have Arab learners' engagement, at the course level, change over the past 4 years? 
RQ 3: How do the patterns and evolution of online learning engagement differ across the Arab countries, and how do they correlate with their ICT and human development conditions? Through this RQ, we seek insights that would help policy makers better project how national-level human and technology development could impact adoption of online learning.

The rest of this paper is organized as follows. In section 2, we present our analysis methodology and define the main variables and factors we analyzed. Section 3 presents and discusses the results of the analysis. Section 4 drives conclusions, and points out future research directions on how the findings can be operationalized by policy makers.

\section{Analysis Methodology}

Since the launch of the Edraak platform in May of 2014, Edraak has been offering educational content for continuous learning since May of 2014 and for K-12 since January 2018. The continuous learning content follows the common MOOC format, and caters to learners interested in post-secondary as well as lifelong learning topics, such as employability skills, arts, language, in addition to specialized STEM courses. In this paper, we analyze the engagement with the continuous learning component only during the time period from January 2015 to December 2018. We chose this time range to be able to compare 4 equal time spans of 1 year each.

When users register, they provide their age, country, and gender (optional) information. As learners then enroll in and engage with online courses on Edraak, the platform records their learning activity. This enables us to determine their levels of engagement with the courses they enrolled in. We used these demographic and activity data elements to compute the analysis variables in Table 1.

For RQ 1, we divided registrants into 4 groups based on their registration year, and compared the distributions of the variables age, country, and gender across the 4 years. For RQ 2, we followed a similar approach, dividing enrollments into 4 groups based on their enrollment year, and compared the distributions of the course engagement variable across the 4 years. 
Table 1. Analysis variables computed from demographic and learning activity data

\begin{tabular}{|c|c|}
\hline Demographics & Course-level engagement \\
\hline $\begin{array}{l}\text { Age (Estimated as } 2019 \text { - } \\
\text { year of birth) }\end{array}$ & \multirow{7}{*}{$\begin{array}{l}\text { Enrollment year: This variable is defined per learner-course } \\
\text { enrollment, and indicates the year when the enrollment occurred. } \\
\text { Course engagement: A nominal variable per enrollment, with the } \\
\text { following } 4 \text { possible values: } \\
0 \text { : The learner interacted with no course components after } \\
\text { enrollment. } \\
\text { 1: The learner interacted with between } 1 \text { and } 50 \% \text { of the course } \\
\text { components } \\
\text { 2: The learner interacted with }>50 \% \text { of the components, but did not } \\
\text { earn the course's certificate of completion. } \\
\text { 3: The learner interacted with }>50 \% \text { of components, and earned the } \\
\text { certificate of completion. }\end{array}$} \\
\hline Country & \\
\hline Gender (Optional) & \\
\hline Registration & \\
\hline Registration year: The year & \\
\hline $\begin{array}{l}\text { when the learner registered on } \\
\text { Edraak }\end{array}$ & \\
\hline & \\
\hline
\end{tabular}

For RQ 3, we studied how demographic distributions of new registrants per year varied across countries by using country and registration year as the first and second dimensions. Furthermore, we studied how registration patterns, by country, correlate with the following country-level indices:

- Information and Communication Technologies (ICT) index [9]: This index is a global measure of countries readiness for and use of information and communication technologies. It is computed from 3 sub-indices:

- Access sub-index: Measures the level of access that the country's population has to ICT

- Use sub-index: Measures the level of use of ICT

○ Skills sub-index: Estimates the skill preparedness of the population for ICT

Our objective behind studying correlation of registration with the ICT index and its sub-indices is to understand how registration varies with more access to, use of, and skill-readiness for ICTs in the Arab countries.

- Gender inequality (GII) index [10]: This index reflects the gender gap in the country in regards to reproductive health, empowerment, and labor market participation. Higher values indicate wider gaps. Our objective behind studying correlations with this index is to explore whether gender inequality conditions in the Arab countries predict gender gaps in online learning on Edraak, and how these gaps have changed over the 4 year period. 


\section{Analysis Results}

For all figures in this section that show distribution by country, we show the top 10 countries in terms of number of registrants on Edraak. These countries, combined, represent $91 \%$ of all registrants and $93 \%$ of all course enrollments on Edraak. The 10 countries are listed in Table 2 below, along with each country's number of registrants as of end of December, 2018, percentage of all Edraak registrants, and its 2-character code used in the following figures. Egypt is currently the country with the highest percentage of registrations.

Figure 1 shows the distribution of all registrants within our analysis window by gender and age as of the end of December, 2018. The figure shows that the overall proportion of males is $4 \%$ higher than females. The mode age group of registrants is 20-24 years old.

Figures 2 and 3 show how gender and age distributions changed by country and year. Figure 2 shows an overall age shift to younger age among registrants in all countries. The average age of registrants dropped by 2 years or more in 8 countries out of 10 .

Figure 3 shows that female registration proportions are increasing consistently along the 4 years and across all countries. Noteworthily, Edraak did not perform any gender-targeted marketing that could account for this difference.

Table 2. Top 10 Arab countries in terms of registrants on Edraak and their 2-character codes

\begin{tabular}{|l|c|c|c|}
\hline Country & Code & Number of registrants & \%of all Edraak registrants \\
\hline Egypt & EG & 421,431 & $28.1 \%$ \\
\hline Algeria & DZ & 222,851 & $14.8 \%$ \\
\hline Jordan & JO & 178,253 & $11.9 \%$ \\
\hline Morocco & MA & 168,535 & $11.2 \%$ \\
\hline Saudi Arabia & SA & 138,847 & $9.2 \%$ \\
\hline Palestine & PS & 79,395 & $5.3 \%$ \\
\hline United Arab Emirates & AE & 46,794 & $3.1 \%$ \\
\hline Syria & SY & 46,922 & $3.1 \%$ \\
\hline Iraq & IQ & 33,477 & $2.2 \%$ \\
\hline Yemen & YE & 29,329 & $2.0 \%$ \\
\hline
\end{tabular}



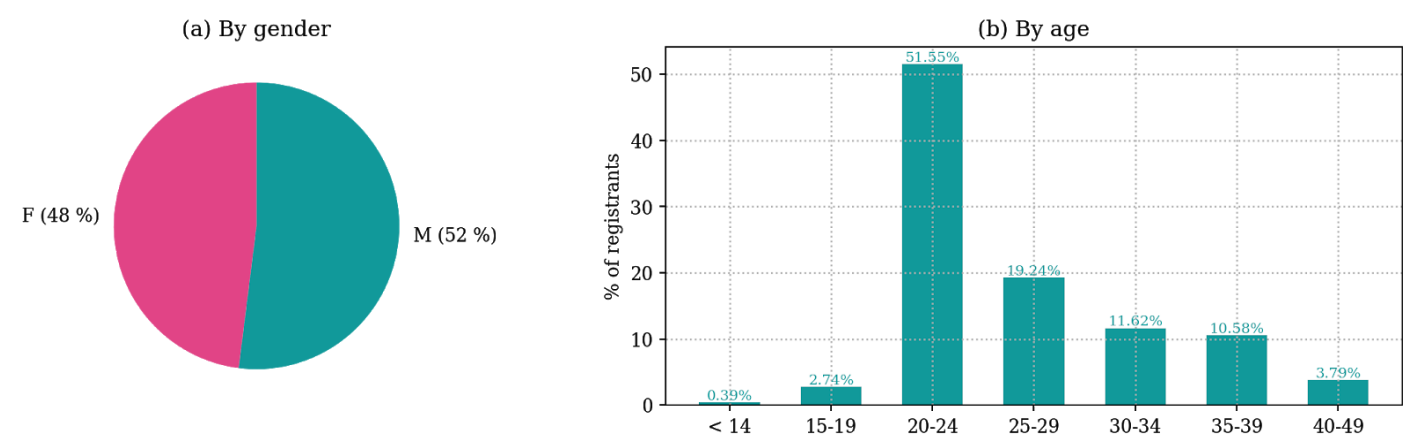

Figure 1. Distribution of all registrants (2015 to 2018) by (a) gender and (b) age

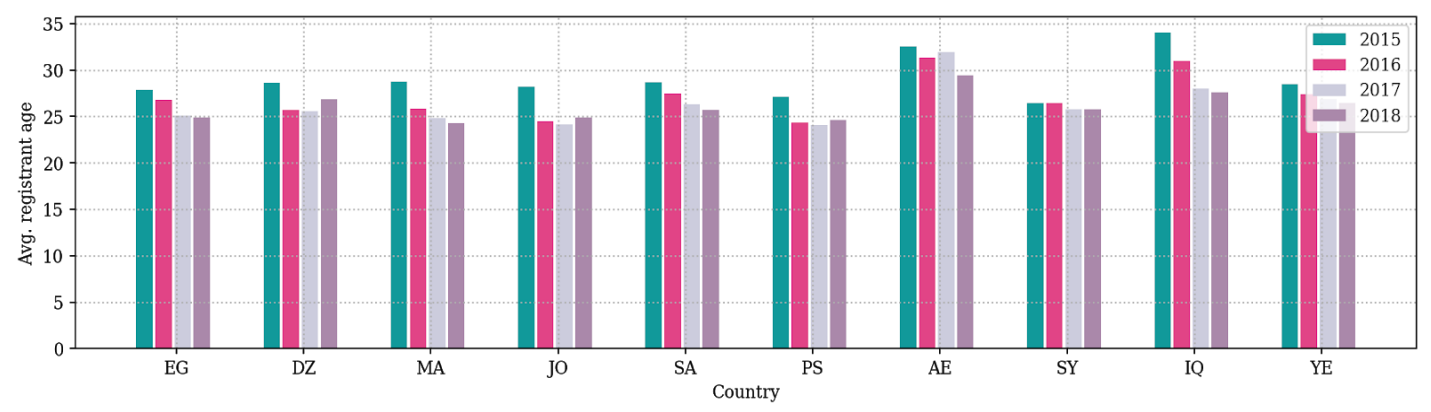

Figure 2. Average registrant age by country and year

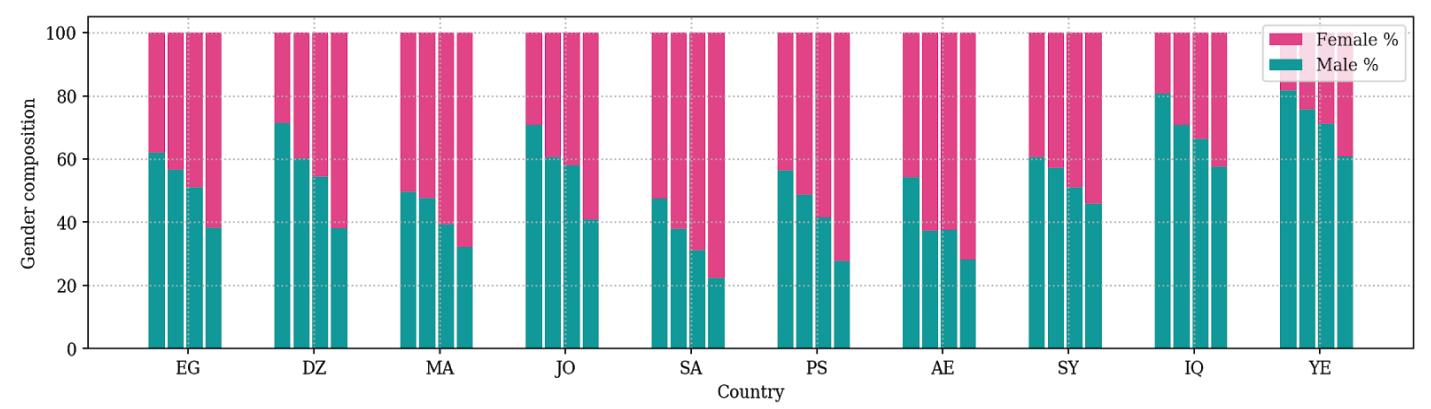

Figure 3. Gender proportions among registrants by country and year

Figure 4 illustrates the variation in engagement rate by country and year. Engagement rate is defined here as the fraction of enrollments where the learner showed up (course engagement $>0$ ) in which the learner engaged with half of the content at least (course engagement $>1$ ). We notice similar patterns across the countries and years, with highest rates in 2018 in most countries. There was no marketing to promote engagement particularly. The most likely explanation for this 
pattern is Edraak's newly introduced content strategy in 2018, through which it focused on creating courses with more learner demand. This suggests the value of localizing content strategies to the regional context.

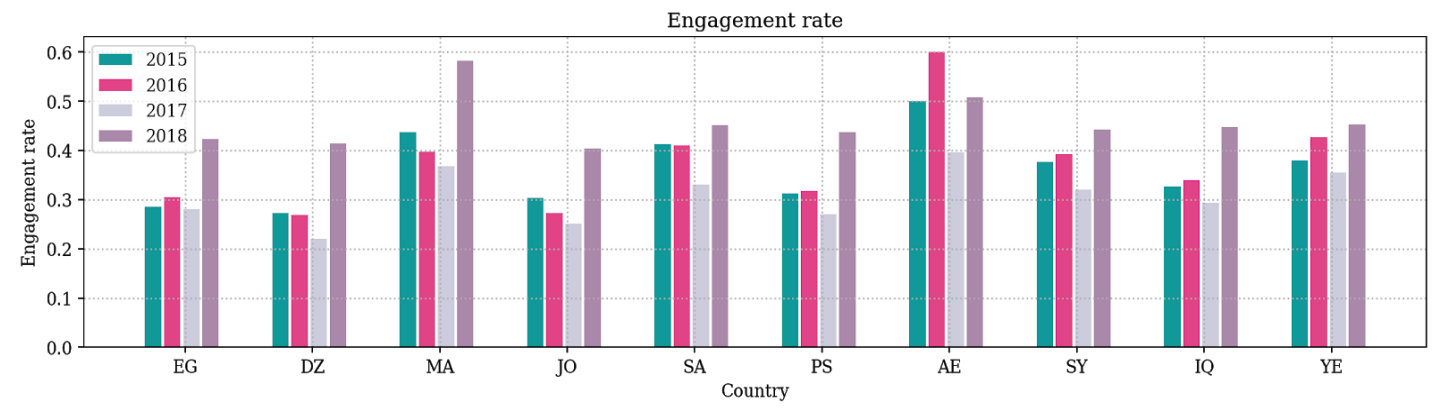

Figure 4. Engagement rate by country and year

Figures 5 and 6 below show how yearly registrations varied by country and year, and the countries' registrants up to December 2017 as percentages of their internet-connected populations as of December 2017.

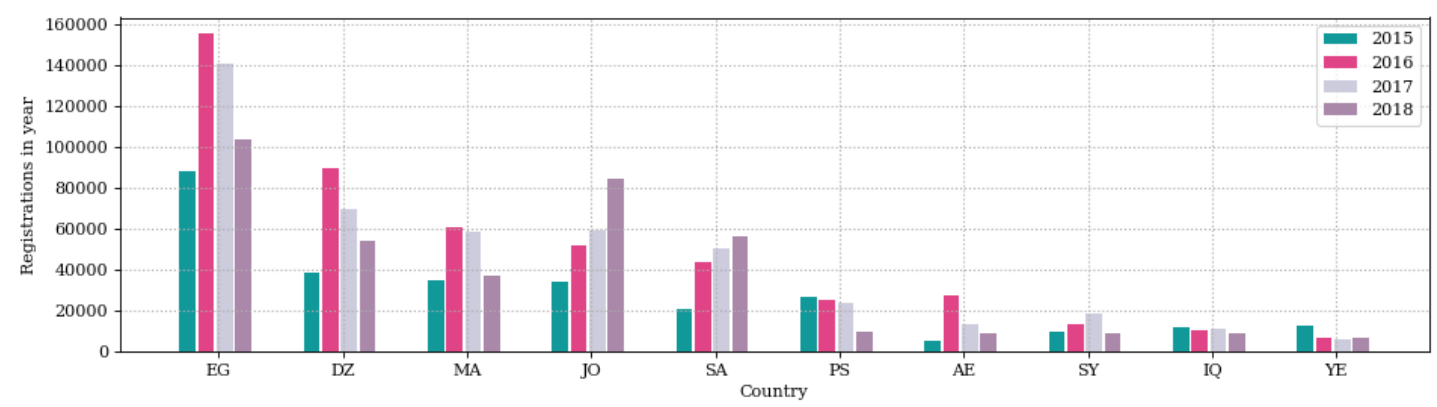

Figure 5. New registrations from each country by year

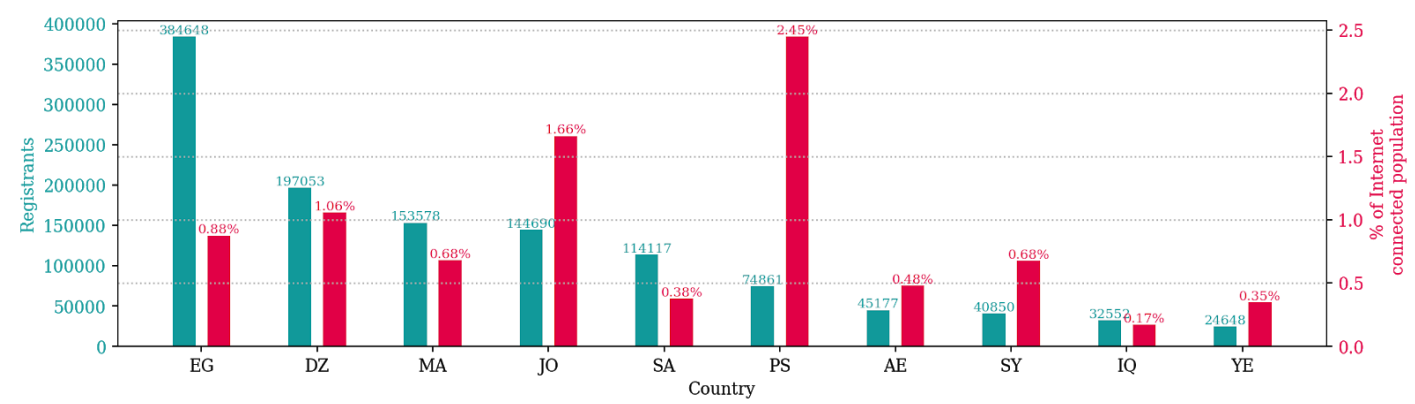

Figure 6. Total registrations as of December 2018 and as a percentage of Internet-connected population 
Figure 5 shows that yearly registrations are rising in countries such as Jordan and Saudi Arabia, and are dropping in other countries such as Egypt and Algeria. Figure 6 points out further significant differences in registrations as percentages of the internet-connected population sizes. Jordan and the State of Palestine have the highest percentages among the 10 countries.

To help recommend directions for future research of the patterns above, we examined their correlation with the ICT and GII indices defined in Section 3. Table 3 shows the significant correlations we identified, all of which are statistically significant $(p \ll 0.001)$.

Table 3. Correlations between registration-related variables and national development indices

\begin{tabular}{|l|c|c|}
\hline Registration-related variable & Index & $\begin{array}{c}\text { Correlation } \\
\text { coefficient } \\
\text { (@) }\end{array}$ \\
\hline$\%$ female registrations in 2015 & GII & -0.72 \\
\hline $\begin{array}{l}\text { \% female registrations in 2018 - \% female } \\
\text { registrations in 2015 }\end{array}$ & GII & -0.33 \\
\hline $\begin{array}{l}\text { Registrations up to 2017, as a percentage of the } \\
\text { December 2017 internet-connected population }\end{array}$ & ICT overall index & -0.44 \\
\cline { 2 - 3 } & ICT access sub-index & -0.71 \\
\cline { 2 - 3 } & ICT use sub-index & -0.32 \\
\cline { 2 - 3 } & ICT skills sub-index & 0.20 \\
\hline
\end{tabular}

We found significant relationships between female-male registration ratios and the countries' gender inequality indices (GII). In 2015, the percentage of females among registrants was negatively correlated $(\rho=-0.72)$ with the GII. This indicates that countries with more gender inequality saw larger gaps in registration on Edraak. The difference in percentage of female registrants between 2018 and 2015 is also negatively correlated $(\varrho=-0.33)$ with GII, which indicates that the gender gap shrank more in countries with better gender equality conditions. These 2 correlations could possibly be linked to the advantage in education, empowerment, and prospective job market participation that countries with better GIIs offer females.

We also found that registrations as a percentage of internet-connected population correlate significantly, but differently, with the Information and Communication Technology (ICT) index and its sub-indices. The correlation of registration per internet-connected capita and the overall ICT index is -0.44 , indicating that higher ICT development scores is not commonly associated with increased access to online learning in Edraak's case. Parsing the correlation, however, we see that the correlation is most negative with the access sub-index and is only positive with the skills sub-index. This suggests the hypothesis that simple provision of access to ICT to a population is not not guaranteed to promote utilization of online learning, unless 
the internet connected population is provided with the skills required to use ICT. Further research of this hypothesis could inform policy makers about the importance of spreading ICT skills alongside ICT access to online learning adoption.

\section{Conclusions and Future Directions}

The results of our analysis show that the landscape of online learning through MOOCs in the Arab world has been shifting since the rise of MOOCs in the region in 2014. Average registrant age is dropping, and female-to-male registration ratios are increasing. Female-to-male ratios were lower in earlier years, and were lower in countries with higher GII. The ratio increased significantly and consistently across the countries and years, and this increase has been larger in countries with better GII. These 2 associations motivate further research into whether countries with outstanding gender gaps in online learning, such as Iraq and Yemen, could expect female engagement with online learning to improve as a result of improving their GII.

Secondly, comparing the yearly registration patterns across countries shows substantial differences, with growing registration in some countries and not others. Understanding these differences and their underlying causes is an important future research direction, because such research may potentially reveal and address factors promoting or limiting online learning adoption in certain countries and population segments.

The correlations between online learning penetration of the internet-connected population and the ICT index and sub-indices also suggests that access to ICT, alone, might be insufficient to promote a population's use of online learning. This could motivate researchers and policy makers to further explore which ICT-related factors promote or restrain adoption of online learning learning in which population segments. Results of this exploration could also inform online learning content and technology designers about audience segments more challenging to reach, so that they can design the online learning environments in a way that is more inviting and manageable for potential learners in these segments. 


\section{References}

[1] "Arab Human Development Report 2016: Youth and the Prospects for Human Development in a Changing Reality", United Nations Development Programme, 2016, pp. 74-78.

[2] "World Employment Social Outlook: Trends for Women, 2018", International Labour Organization, 2018, pp. 7-8.

[3] www.edraak.org

[4] www.rwaq.org

[5] www.doroob.sa

[6] K. Abouchedid, G. Eid, "E-learning challenges in the Arab world: Revelations from a case study profile". Quality Assurance in education, 12 (1), 2004, pp. 15-27.

[7] T. Dillahunt, B. Z. Wang, S. Teasley, "Democratizing higher education: Exploring MOOC use among those who cannot afford a formal education". The International Review of Research in Open and Distributed Learning, 15 (5), 2014.

[8] J. Ruiperez-Valiente, S. Halawa, J. Reich, "Multiplatform MOOC Analysis: Comparing Global and Regional Patterns in edX and Edraak", accepted for publication in the $6^{\text {th }}$ ACM Conference on Learning at Scale, Chicago, USA, June, 2019.

[9] "Measuring the Information Society Report 2017 - Volume 1", The International Telecommunications Union, 2017, Chapter 2, pp. 25-30.

[10] G. Ferrant, "The Gender Inequalities Index (GII) as a New Way to Measure Gender Inequalities in Developing Countries”, Sciences, New York, 2010, pp.106-112. 